\title{
INVESTIGATION OF HOT CORROSION BEHAVIOUR OF UNCOATED AND WC- 17CO COATED SAMPLES IN AGGRESSIVE MOLTEN SALT ENVIRONMENT
}

\author{
GURMAIL SINGH $^{1} \&$ SOURAV CHOUDHARY ${ }^{2}$ \\ ${ }^{I}$ Assistant Professor, Department of Mechanical Engineering, Chandigarh University, Gharuan, Punjab, India \\ ${ }^{2}$ Research Scholar, Department of Mechanical Engineering, Chandigarh University, Gharuan, Punjab, India
}

\begin{abstract}
Hot corrosion is usually a significant issue in power plant's boilers. The alloys and metals get corroded, once exposed to high temperature corrosion in air, or in actual boiler environment in power plants. In order to protect materials; thermal spraying is a newly developed technology that enhances high temperature corrosion resistance of boiler steels. In the present study, WC-17Co coating were deposited by HVOF technique on substrate ASTM-SA213-T91. Subsequently; high temperature corrosion behavior of uncoated and WC-17Co coated substrate T91 was investigated in molten salt environment at an elevated temperature of $900^{\circ} \mathrm{C}$ for 50 cycles. The experimental cyclic study consisted a cycle of 1 hour heating of samples in SiC tube furnace, followed by 20 minutes of cooling in room temperature. Surface morphologies of corroded samples were carried out by SEM/EDS and XRD analysis. In the results, bare material is corroded with intense peeling and spalling. But on the other side, WC-17Co coating performed better than the uncoated steel substrate.
\end{abstract}

KEYWORDS: HVOF, Thermal Spray, XRD \& Tube Steel

Received: Jun 16, 2017; Accepted: Jul 10, 2017; Published: Jul 19, 2017; Paper Id.: IJMPERDAUG201718

\section{INTRODUCTION}

The high temperature corrosion is very serious issue in day to day life, as elevated temperature has importance in many power plants. The problem is known as hot corrosion that is caused due to the combination of hot temperature along with contaminants from surroundings and burning of low grade fuels. Various products like sodium, sulphur, vanadium and chlorine accelerate the rate of degradation of the turbine and boiler tubes [1,2]. Hot corrosion causes frequent plant shut downs, wastage of precious and expensive material resources, loss of products, and as well as the cut backs the potency and results to expensive maintenance [3].

The continuously rising cost of materials has been a great concern in the mind of researchers in the recent times. The surface coating method has been given more importance to meet this challenge in the area of technology; where materials have to operate in harsh conditions of corrosive surroundings, pressure and temperature etc [4]. The thermal spray is a recent technology to deposit coatings of metallic, ceramic and some polymeric materials either in the form of powder or wire [5]. The high velocity oxy fuel (HVOF) spray is one of thermal spray methods, which is widely utilized in several industries, owing to its flexibility and price effectiveness. The coatings created by HVOF have low porosity, higher hardness, superior bond strength and less decarburization than other spraying methods [6].

The materials used as coatings for high temperature applications must have the ability to provide a stable, slow growing surface oxide, so as to produce smart surface behavior [7]. The present study is oriented towards to 
achieve hot corrosion protection. A comparative hot corrosion behavior of two commercially available powders is studied for protection of valuable material.

\section{EXPERIMENTAL PROCEDURE}

\section{Materials}

A boiler tube steel ASTM-SA213-T91 was used as substrate material. The composition details of T-91 steel are given in Table 1. The coating powder WC-17CO had been deposited on substrate material by HVOF spraying process. The samples cut in rectangular shape having dimensions of approximately $20 \mathrm{~mm} \times 10 \mathrm{~mm} \times 5 \mathrm{~mm}$ by power milling machine from tubes. The specimens were polished down with emery papers of 180 grit sizes, and afterwards mirror polished using cloth polishing wheel machine, with $1 \mu \mathrm{m}$ lavigated alumina powder suspension.

Table 1: Nominal Chemical Composition (wt \%) of ASTM SA213-T91 Boiler Tube Steel

\begin{tabular}{|c|c|c|c|c|c|c|c|c|}
\hline $\mathrm{C}$ & $\mathrm{Si}$ & Mn & P,S Max & Cr & Mo & Ni Max & V & Al Max \\
\hline $\mathbf{0 . 0 7 - 0 . 1 4}$ & $\mathbf{0 . 2 0 - 0 . 5 0}$ & $\mathbf{0 . 3 0 - 0 . 6 0}$ & $\mathbf{0 . 0 2}$ & $\mathbf{8 . 0 - 9 . 5}$ & $\mathbf{0 . 8 5 - 1 . 0 5}$ & $\mathbf{0 . 4}$ & $\mathbf{0 . 1 8 - 0 . 2 5}$ & $\mathbf{0 . 0 1 5}$ \\
\hline
\end{tabular}

\section{Spraying Process}

Prior to the coating deposition, the substrate surfaces were grit blasted with $\mathrm{Al}_{2} \mathrm{O}_{3}$ (grit 60) using blasting machine, in order to achieve good roughness for adhesion of coatings. The coatings powder was deposited from Metalizing Equipment Pvt. Ltd., Jodhpur (India) with Hipojet-9600 HVOF spraying system. The standard spray parameters were generally used to deposit the WC-17Co coating, as shown in Table 2. The average coating thickness achieved approximately $150-200 \mu \mathrm{m}$. The process parameters, including spray distance were kept constant, throughout the coating process.

Table 2: HVOF Spray Process Parameters

\begin{tabular}{|l|l|}
\hline \multicolumn{1}{|c|}{ Oxygen Flow Rate } & \multicolumn{1}{c|}{ 200 SLPM } \\
\hline Fuel (LPG) flow rate & 50 SLPM \\
\hline Air-flow rate & $900 \mathrm{SLPM}$ \\
\hline Spray distance & $20 \mathrm{~cm}$ \\
\hline Powder feed rate & $25-30 \mathrm{gm} / \mathrm{min}$ \\
\hline Fuel pressure & $6.00 \mathrm{~kg} / \mathrm{cm}^{2}$ \\
\hline Oxygen pressure & $8.00 \mathrm{~kg} / \mathrm{cm}^{2}$ \\
\hline Air pressure & $6.00 \mathrm{~kg} / \mathrm{cm}^{2}$ \\
\hline
\end{tabular}

\section{Characterisation of Coating}

The as-sprayed as well as corroded specimens were subjected to surface SEM/EDS and XRD analysis for the identification of various compounds and corrosion products. The XRD analysis was carried out with X-Ray Diffractometer at (model: ME210, Make Rigaku Corporation, Japan; Thapar University, Patiala) to recognize various phases formed on the surface. The specimens were scanned with speed of $2^{\circ} / \mathrm{min}$ in $2 \theta$ range of $20^{\circ}$ to $110^{\circ}$ and the intensities were recorded. The surface morphology of different samples was observed by using scanning electron microscope (FEI, Quanta200F, and Made in Czech Republic, at IIT Roorkee) with EDAX Genesis software attachment. 


\section{RESULTS}

\section{Characterization of As-Sprayed Samples}

\section{XRD and SEM/EDS Analysis of WC-17Co Coated Substrate}

The X-ray diffraction pattern of the as-sprayed WC-Co coating is presented in Figure 3. Formation of tungsten aluminum carbide; tungsten carbide and cobalt nickel are main phase indentified in XRD. The SEM/EDS analysis of assprayed WC-17Co coating (Figure 4a\&b) shows the presence of significant amount of carbon (13.78\%), that indicates deposition of carbide phase. Moreover, the microstructure of the as-sprayed coating (Figure 4a) shows reasonably uniform distribution of the primary carbides.

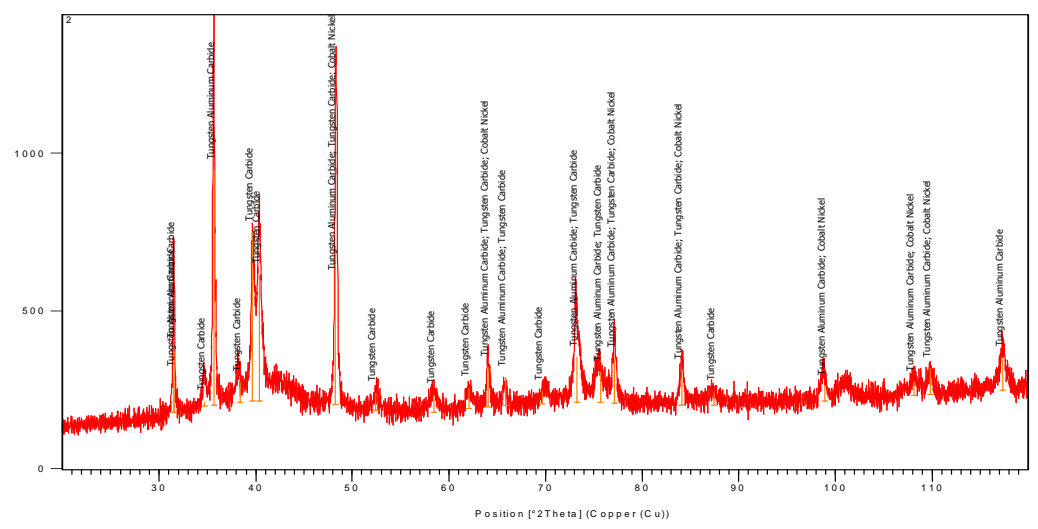

Figure 1: XRD Diffraction Pattern of as-Sprayed WC-17Co Coated T-91 Boiler Steel

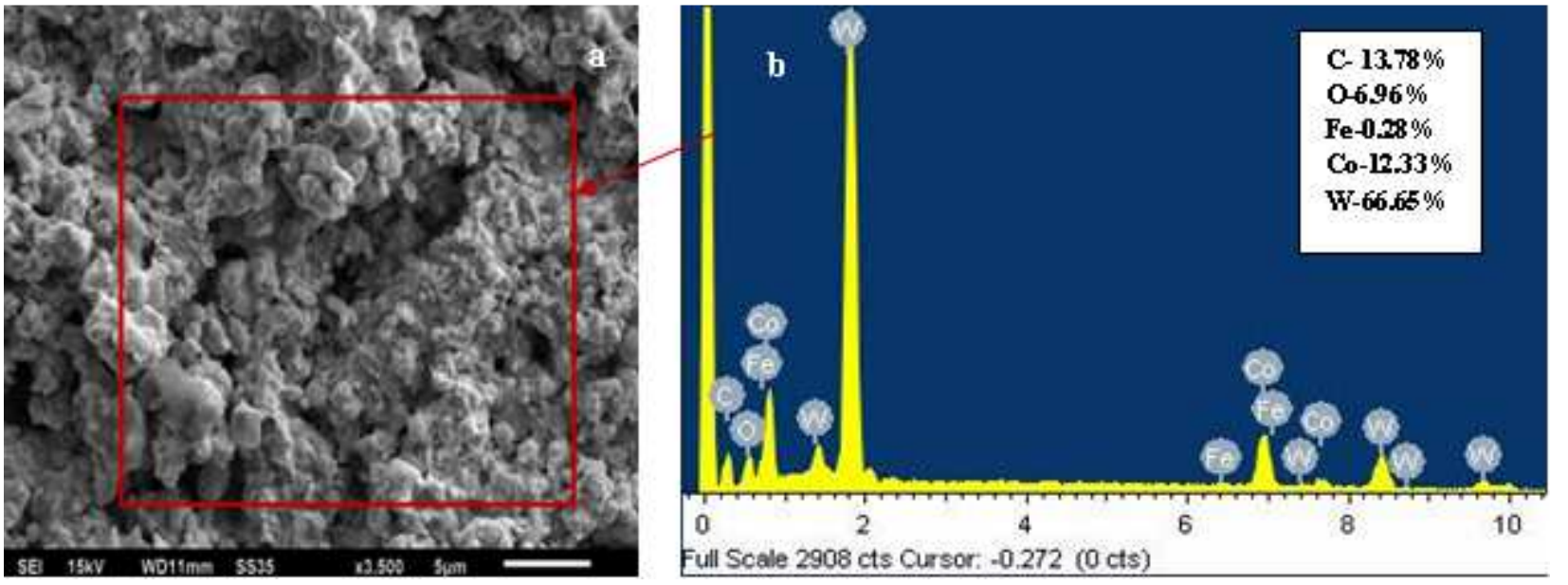

Figure 2: (a) SEM Image \& (b) EDS Pattern of WC-17Co Coated T91 Boiler Steel Elemental Composition (Wt \%)

\section{Corroion Kinetics of Samples}

Figure 5 refers the corrosion kinetics of uncoated and coated T-91 samples that were examined for 50 cycles at $900^{\circ} \mathrm{C}$ in aggressive environment of molten salt $\mathrm{Na}_{2} \mathrm{SO}_{4}-60 \% \mathrm{~V}_{2} \mathrm{O}_{5}$. The uncoated substrate showed accelerated corrosion and continuous gain of weight. After $2^{\text {nd }}$ cycle peeling of substrate was observed. A continuous spalling and severely corrosion with grey color of the layers turned to dull grey after $10^{\text {th }}$ cycle of uncoated sample noticed, which was continued till $50^{\text {th }}$ cycle. On other side; WC-17\%Co coated sample showed more weight gain up to $8^{\text {th }}$ cycle ,then coating layer peeled off from substrate up to $12^{\text {th }}$ cycle in oxidation after then it behave like bare substrate and weight continuously 
gained up to $50^{\text {th }}$ cycle.

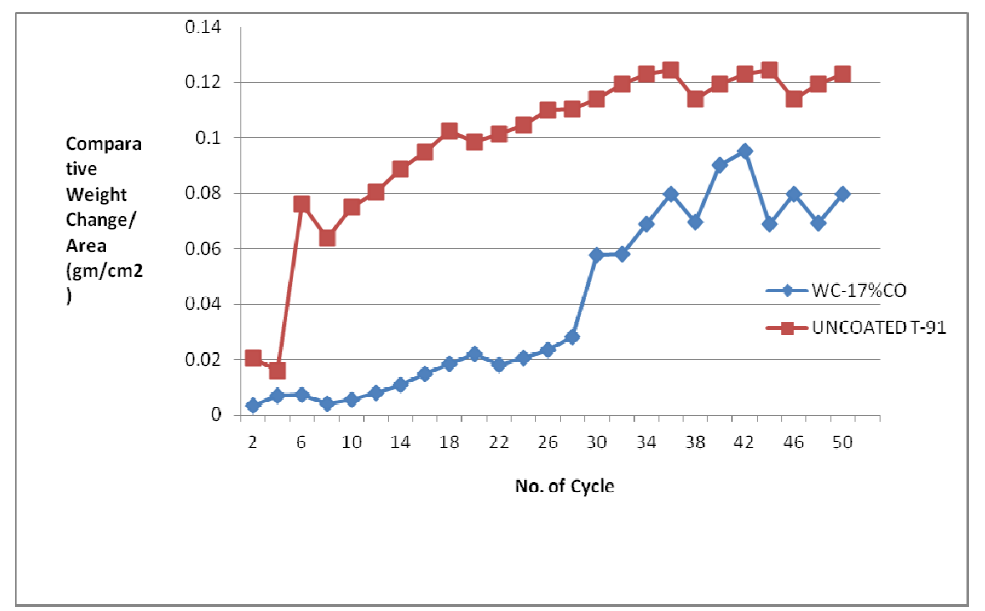

Figure 3: Comparative Weight Change/Area $\left(\mathrm{G} / \mathrm{Cm}^{2}\right)$ Vs Number of Cycles Plot Studies in Molten Salt Environment at $900^{\circ} \mathrm{c}$ for 50 Cycles

Characterization of Corroded Samples

SEM/EDS analysis of Corroded Uncoated Substrate

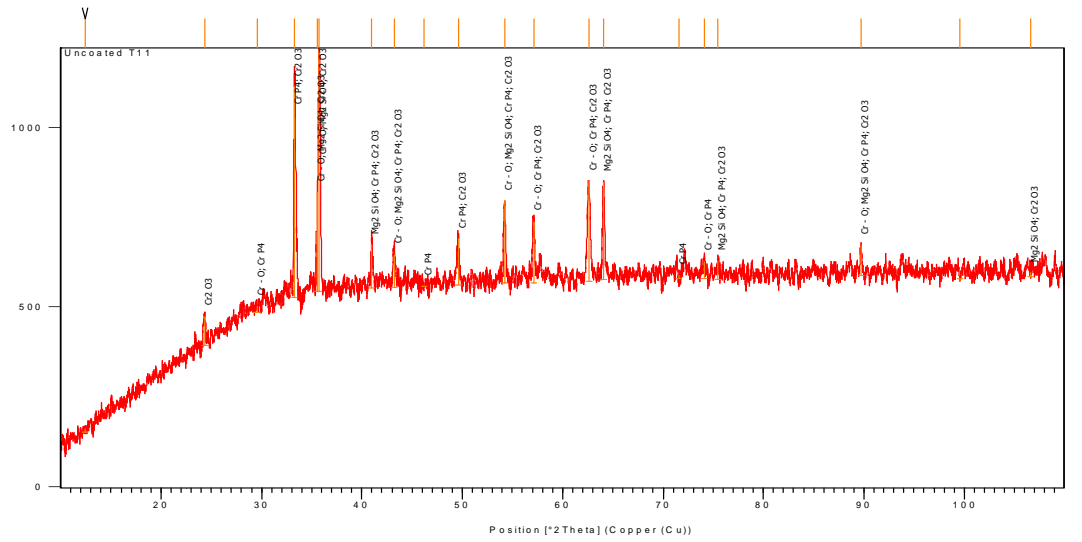

Figure 4: XRD Pattern of Bare T-91 Boiler Steel after Hot

Corrosion in Molten Salt Environment at $900^{\circ} \mathrm{C}$
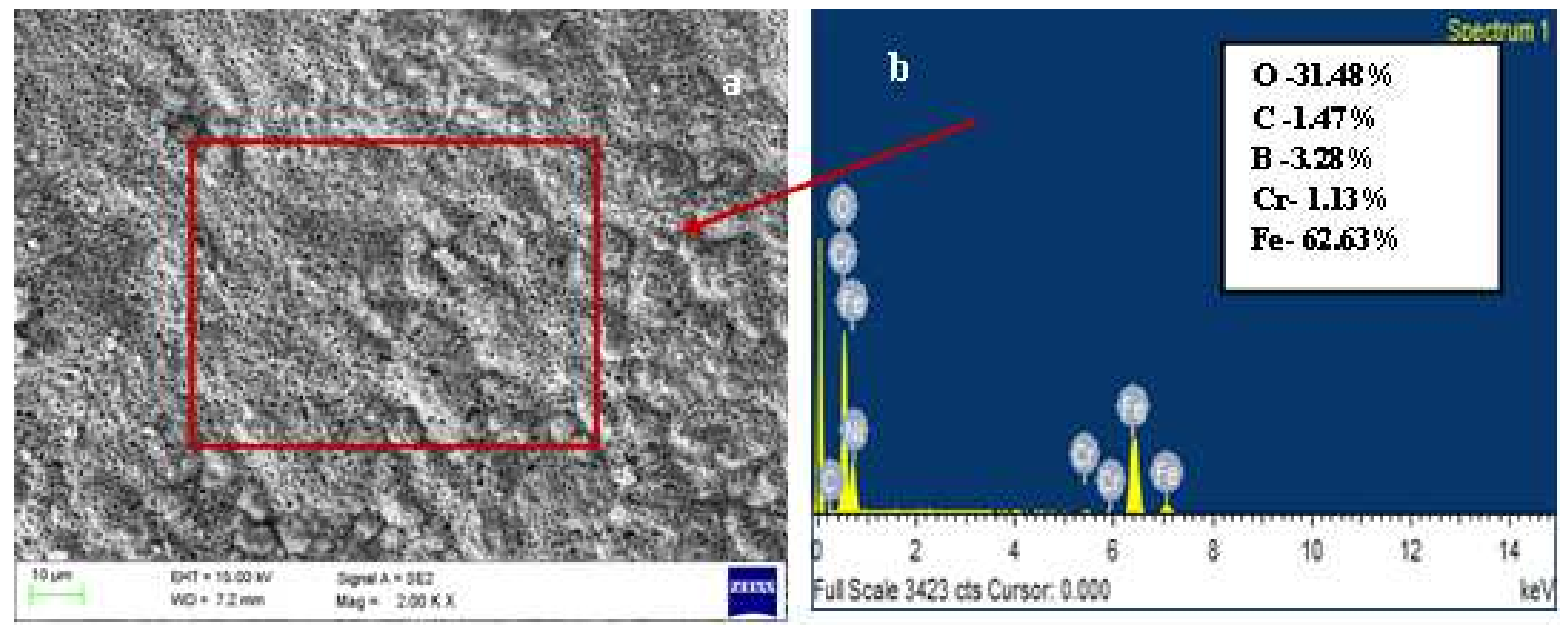

Figure 5: (a) SEM Image and (b)EDS Pattern of Corroded Bare Boiler Steel with Elemental Composition(Wt.\%) 
The uncoated substrate steel showed (Figure 7a\&b) intense spalling, peeling off scale and weight gain found in the aggressive environment at $900^{\circ} \mathrm{C}$. A large amount of the presence of $\mathrm{O}(31.48 \%)$ and $\mathrm{Fe}(62.63 \%)$ leads the formation of $\mathrm{Fe}_{2} \mathrm{O}_{3}$.

\section{XRD, SEM/EDS analysis of Corroded WC-Co Coated Substrate}

The XRD and SEM analysis of WC-17Co coated specimen after cyclic air oxidation is shown in Figure 9.

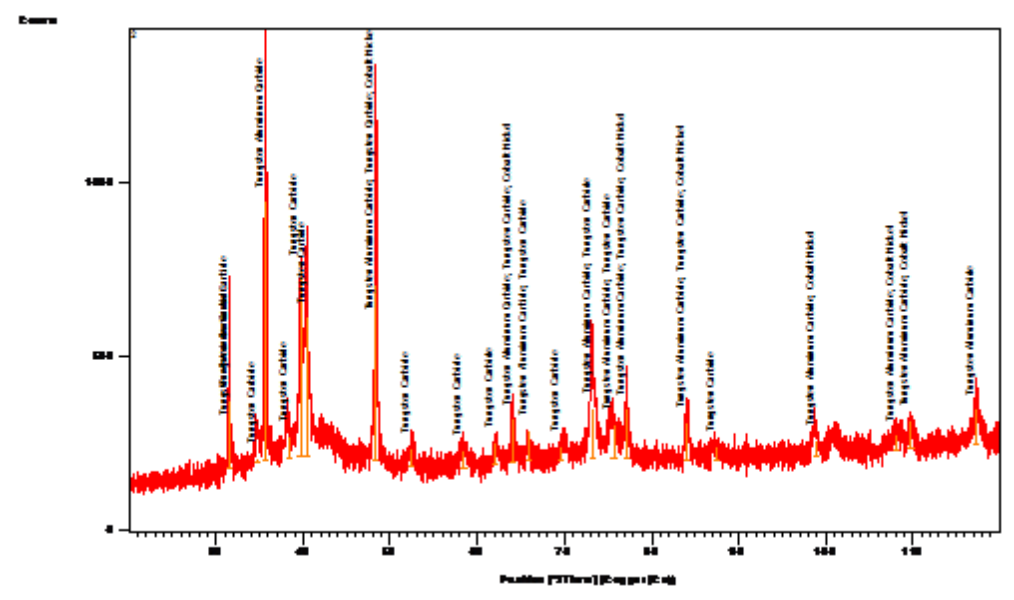

Figure 6: XRD Diffraction Pattern for Corroded WC-Co Coated T-91 Boiler Steel Elemental Composition
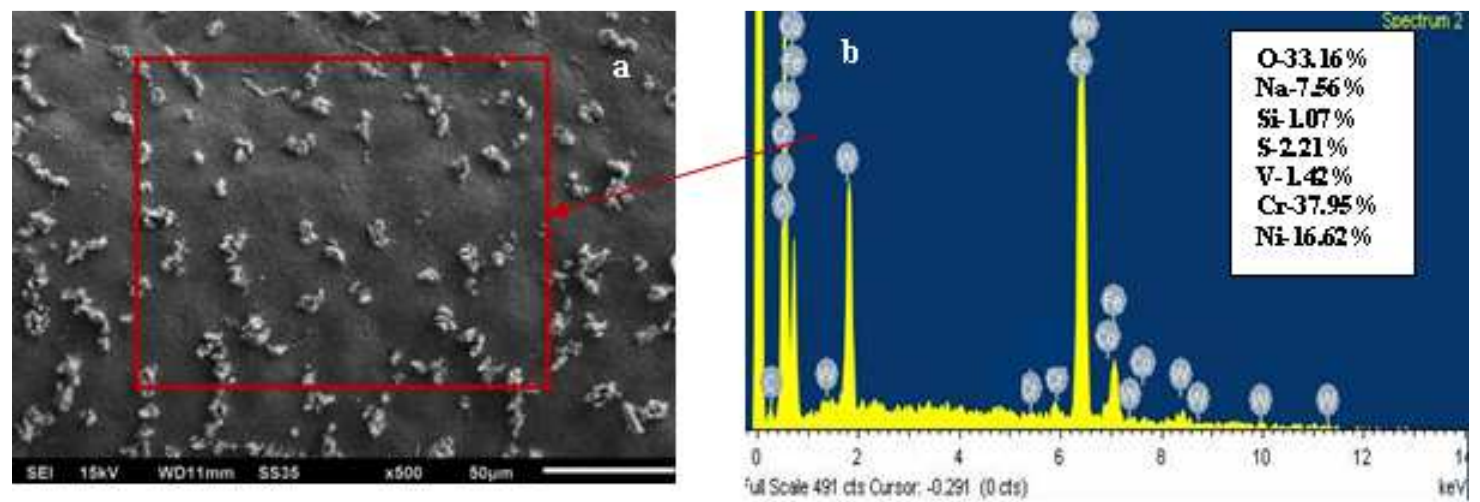

Figure 7: (a) SEM Image and (b)EDS Pattern of Corroded WC-17\% Co Coated Boiler Steel with Elemental Composition(Wt.\%)

\section{DISCUSSIONS}

The WC-17Co powders was successfully deposited on T91 substrate by HVOF spray process. The porous coatings can do harm to the persisancy of corrosion resistance during testing [8-9]. Very good dense coatings with few porosity had been deposited that provided better corrosion resistance. Many other researchers suggested that the void reduction of interparticles is enhanced mainly by mechanical interlocking among the fine-fragmented particles with highly irregular shapes, therefore the particles are well packed and interlocked with each other in coating[10]. As-sprayed WC$17 \%$ Co coating shows the presence of phases with the composition (C-13.78\%, O-6.96\%, Fe-0.28\%, Co-12.33\% and W$66.65 \%$ ). The XRD pattern (Figure 1) of coating exhibits primary phases namely; tungsten aluminum carbide, tungsten carbide and cobalt nickel. The presences of $\mathrm{W}_{2} \mathrm{C}$ along with tungsten aluminum carbide in as-sprayed coatings indicate that 
the decomposition of carbides has taken place during the HVOF spraying [11]. The surface morphologies of the as-sprayed WC-17Co coating showed deposition and uniform distribution of the primary carbide phase. Fractured large carbide has also seen on the substrate under high impinging velocities in HVOF process [12]. Some regions of the binder have seen bright and grey area of different shades as shown in Figure 2. Some micro cracks also visible in coated surface. The good content of tungsten $(66.65 \%)$ on coated surface might lead to improve in mechanical properties [12].

The uncoated steel showed higher rates of hot corrosion in comparison with its coated counterparts [Figure 3]. $\mathrm{Fe}_{2} \mathrm{O}_{3}$ was observed as a main phase in the oxide scale of the uncoated steel. This was further supported by FE-SEM/EDS analysis (Figure $5 \mathrm{a} \& \mathrm{~b}$ ), which reveals higher amounts of $\mathrm{Fe}$ and $\mathrm{O}$ in the surface of scales of the uncoated substrate. The presence of $\mathrm{Fe}_{2} \mathrm{O}_{3}$ in the scale has been reported as nonprotective. The coating of WC-17Co removed under the aggressive environment of high temperature oxidation slowly from some points. In oxide scale of WC-17Co coated steel, $\mathrm{Fe}_{2} \mathrm{O}_{3}$ was observed as main phase. Results shows WC-17Co provide protection in aggressive environment which also observed by Sidhu et al. [13]

\section{CONCLUSIONS}

- WC-Co coating has been sucessfully deposited by HVOF spraying technique on ASTM-SA213 T-91 boiler steel. The coating thickness has been found along the cross-section of sample in the range of 150-200 $\mu \mathrm{m}$.

- The WC-17Co coated specimen, the main phases formed were tungsten aluminum carbide, tungsten carbide and cobalt nickel.

- The uncoated substrate steel showed intense spalling, peeling off scale and continuous weight gain.

- WC-17Co coatings can provide good corrosion resistance in actual boiler environment.

- The HVOF spray coated WC-17Co was found be better than the uncoated specimen to protect the boiler steel substrate from hot corrosion.

i.e. WC-17Co coated Steel > Uncoated substrate

\section{REFERENCES}

1. H.P Nielsen, F.J Frandsen, K. Dam-Johansen, L.L Baxter (2000), "The implications of chlorine associated corrosion operation of biomass fired boilers”, Prog. Energy Combust Sci. vol. 26, pp. 283-298.

2. H. Habibi, S.M. Guo (2015), "Evolution of hot corrosion behavior of $\mathrm{YSZ}_{\mathrm{SZ}} \mathrm{Ta}_{2} \mathrm{O}_{5}$ composites with different $\mathrm{YSZ} / \mathrm{Ta} a_{2} \mathrm{O}_{5}$ ratios", Int. J. Appl. Ceram. Technol. vol. 12 pp 542-550

3. P.E. Chandler, M.B.C. Quigley (1986), "The application of plasma-sprayed coatings for the protection of boiler tubing", Proceedings of the 11th International Thermal Spraying Conference, Montreal, Canada, pp. 29-35.

4. R.A. Rapp, Y.S. Zhang (1994), "Hot Corrosion of Materials: Fundamental studies", materials science and engineering, vol. 46 pp $47-55$.

5. S. Amin and H. Panchal (2016), "A Review on Thermal spray coating process", International Journal of current trends in Engineering and Research, vol 2, pp. 556-563.

6. C. Wagner, (1956), "Oxidation of alloys involving noble metals", J. Electochem. Soc. Vol.103,pp571-580

7. Metals Handbook. ASM Publication, Vol.10, (1975), Metals Park OH, USA. 
8. W.M. Zhao, Y. Wang, L.X. Dong, K.Y. Wu, and J. Xue (2005),"Corrosion mechanism of NiCrBSi coatings deposited by HVOF”, Surf.Coat. Technol, vol. 190, pp. 293-98.

9. N.F. Ak, C. Tekmen, I. Ozdemir, H.S. Soykan, E. Celik (2003), “NiCr coatings on stainless steel by HVOF technique”, Surface and Coatings Technology, vol. 174-175,pp. 1070-1073.

10. D.S. Rickerby, M.R.Winstone, (1995). “Coatings for gas turbines”, Materials and Manufacturing Processes, vol. 7(4), pp. $495-526$.

11. Somasundaram, B., Kadoli, R. and Ramesh, M.R. (2014) "Evaluation of cyclic oxidation and hot corrosion behavior of HVOF-Sprayed WC-Co/NiCrAlY Coating”, Journal of Thermal Spray Technology, vol. 23(6), pp. 1000-100

12. Ramesh, M.R., Prakash, S., Nath, S.K., Sapra, P.K. and Venkataraman, B. (2010) "Solid Particle Erosion of HVOF Sprayed WC-Co/NiCrFeSiB Coatings", vol. 269, pp. 197-205.

13. Sidhu, H.S., Sidhu, B.S. and Prakash, S. (2006) "Hot corrosion behavior of HVOF Sprayed coatings on ASTM SA213-T11 steel", Journal of Thermal Spray Technology, vol. 16(3), pp. 349-354. 
